\title{
Glaucoma medications: issues with adherence in a tertiary hospital in Nigeria
}

\author{
STELLA NGOZI ONWUBIKOA, B, E-G, NKIRU ZUADA NWACHUKWU, B, D-G,
} BONIFACE IKENNA EZEA, c, D, G

Department of Ophthalmology, University of Nigeria Teaching Hospital, Ituku-Ozalla, Enugu, Nigeria

A - Study Design, B - Data Collection, C - Statistical Analysis, D - Data Interpretation, E - Manuscript Preparation, F - Literature Search, G - Funds Collection

Summary Background. Patient adherence with glaucoma medical therapy remains a global challenge.

Objectives. To determine the prevalence of non-adherence and identify the determinants and deterrents to glaucoma medications in Enugu, southeast Nigeria.

Material and methods. This study adopted a cross-sectional, descriptive, hospital-based survey involving 114 glaucoma patients on topical medications. They were recruited from the ophthalmic clinic of the University of Nigeria Teaching Hospital, Enugu. Information on their socio-demographic characteristics, clinical profile and issues of adherence with glaucoma medications were collected using a pre-tested, close-ended, interviewer-administered questionnaire. The data collected was analysed using SPSS version 21. Bivariate analysis was done to identify the associations of different factors of adherence with glaucoma medications. The level of significance was set at $p<0.05$.

Results. The participants were comprised of 58 males $(50.9 \%)$ and 56 females $(49.1 \%)$, with a mean age of $60.0 \pm 14.8$ years. Most were mainly on two or less glaucoma medications $(92(80.7 \%))$ and were diagnosed with glaucoma for less than 5 years (73 (64.0\%)). $42(36.8 \%)$ participants were non-adherent with their glaucoma medications. Assisted administration of glaucoma medication was the most important determinant of non-adherence to medication. Gender, good/fair vision, distance from the pharmacy, knowledge of the disease and educational status also contributed. Cost was the major deterrent (59 (51.7\%)) to adherence with glaucoma medications. Conclusions. The prevalence of non-adherence with medications among glaucoma patients in Enugu was high. Assisted drug administration was the most significant determinant, while the cost of drugs was a major deterrent to non-adherence with glaucoma medication.

Key words: glaucoma, compilance, Nigeria.

Onwubiko SN, Nwachukwu NZ, Eze BI. Glaucoma medications: issues with adherence in a tertiary hospital in Nigeria. Fam Med Prim Care Rev 2020; 22(4): 302-306, doi: https://doi.org/10.5114/fmpcr.2020.100436.

\section{Background}

In Nigeria, glaucoma is the most common cause of irreversible blindness, accounting for more than $16 \%$ of blindness [1]. Typically, it is characterised by late presentation of advanced-stage primary open angle glaucoma (POAG) [2-4], requiring long-term use of ocular hypotensive agents, even after trabeculectomy [5].

Documented evidence has shown that persistent use of intraocular pressure lowering medications delays glaucoma disease progression, as well as reduces vision loss and the risk of blindness $[6,7]$. However, this is still far from reality, as patient adherence with glaucoma medical therapy remains a global challenge.

The prevalence of non-adherence was observed to be $51.6 \%$ in the UK [8], 36\% in Alabama, USA [9], and $60 \%$ in a predominantly African American population [10]. It was reported to be $16.9 \%$ in Boston, USA [11], 28.2\% in Canada [12], 27.3\% among a Dutch population [13], 6\% in southern India [14] and 67.5\% in Ethiopia [15]. In Nigeria, previous studies reported a range of 28 to $72.8 \%$ prevalence of non-adherence $[2,16,17]$. However, varying definitions of adherence were used in these studies, ranging from self-reported adherence $[2,10-17]$, electronic dose monitor [9], pharmacy claims [10,12], electronic medical records [11], physicians' reports or a combination of two or more of these [12].
Possible factors associated with non-adherence have been explored. Age $[8,9,11,15]$, marital status [14], level of education $[9]$, income $[9,15]$, race $[9,10]$, forgetfulness $[10,13]$, technique of instillation $[13,14,16]$, number of medications and frequency of use [12], duration [17] and stage of glaucoma [15], co-morbid conditions [9] and living conditions [12] have been reported to influence adherence with glaucoma medications.

An in-depth understanding of these determinants of non-adherence with glaucoma medications offers a useful guide for intervention measures that could improve patients' clinical outcomes among the studied population [18].

In a resource-limited environment typical of our setting, where electronic monitoring, pharmacy claims or health insurance are almost non-existent, self-reported adherence with its inherent bias becomes handy to generate data for appropriate intervention aimed at improving the clinical management of glaucoma in the study area and elsewhere with similar settings.

This study was designed to determine the prevalence, determinants and deterrents to glaucoma medication in Enugu, southeast Nigeria.

\section{Material and methods}

\section{Study area}

Patients attending the ophthalmic clinic of the University of Nigeria Teaching Hospital (UNTH) were recruited for the study. 
The UNTH, Enugu, is one of the first generation tertiary health facilities in Nigeria, established in 1971. It is located in the state of Enugu, southeast Nigeria, within the tropical rainforest climatic zone. It provides tertiary health care services in all major medical and surgical specialties. The UNTH's Ophthalmology Department provides inpatient and outpatient eye care services to all five states in the southeast and some states in the southern geopolitical zones.

\section{Inclusion criteria}

Glaucoma patients on topical medications, who attended the eye clinic during the study period and voluntarily gave informed consent to participate.

\section{Exclusion criteria}

Glaucoma patients who are not on topical glaucoma medications; those with recent successful glaucoma surgeries and LASER treatment.

\section{Ethical consideration}

Ethical clearance compliant with the 1964 Helsinki Declaration was obtained from the University of Nigeria Teaching Hospital's Medical and Health Research Ethics Committee.

\section{Study period}

The study was conducted from January to June 2018.

\section{Sample size calculation}

Sample size was calculated using Fischer's formula, as shown below:

Sample size $(n)=\underline{Z}_{\underline{1-a / 2^{2}}} \frac{P(1-P)}{d^{2}}$,

where $Z_{1-a / 2}=$ the standard normal variate (at $5 \%$ type 1 error $(p<0.05)$, which is 1.96

$P=$ prevalence of glaucoma in a similar previous study [19]

$d=$ absolute error or precision, which is 0.05

$$
\begin{aligned}
& n=\frac{1.96^{2}}{(0.05)^{2}} \times 0.94(1-0.94) \\
& =\frac{3.8416 \times 0.0564}{0.0025} \\
& =86.7=87
\end{aligned}
$$

$10 \%$ attrition (9) was added

Number of participants $=87+9=106$

At the end of the study, 114 participants took part.

\section{Sampling technique}

The purposive sampling technique was used to select participants for the study.

\section{Study design}

This was a cross-sectional, descriptive, hospital-based survey involving 114 participants on glaucoma medications who attended the ophthalmic clinic during the study period. Information on their socio-demographic characteristics, clinical characteristics and issues of adherence with glaucoma medications was collected using a close-ended, interviewer-administered questionnaire.

\section{Study instrument}

This was a pre-tested, 26-item questionnaire comprising two sections: firstly, the socio-demographic and clinical information and visual assessment of participants; secondly, the types of glaucoma medications, adherence to the prescription, understanding the reason for use and possible deterrents to use.

\section{Study definition}

Adherence is considered as administering medications as prescribed over the previous week.

\section{Data management}

Data was cleaned, coded and analysed using the Statistical Package for Social Sciences (SPSS) software for Windows, version 21.0 (SPSS Inc, Chicago, Illinois, USA). Data was subsequently categorised by socio-demographic variables and subjected to descriptive statistical evaluation to yield frequencies, percentages and proportions. Bivariate analysis was done to identify associations of different factors with adherence to glaucoma medications. The level of significance was set at $p<0.05$.

\section{Results}

The participants were comprised of 58 males $(50.9 \%)$ and 56 females (49.1\%), with a mean age of $59.59 \pm 14.8$ years, and more than $90 \%$ were aged 40 and above. The majority were married and had at least primary school education. The socio-demographic characteristics of participants are shown in Table 1.

\begin{tabular}{|l|l|}
\hline \multicolumn{2}{|l|}{ Table 1. Socio-demographic characteristics of participants } \\
\hline Characteristics & $n(\%), n=114$ \\
\hline Age & $3(2.6)$ \\
$1-20$ & $8(7)$ \\
$21-40$ & $45(39.5)$ \\
$41-60$ & $56(49.1)$ \\
$61-80$ & $2(1.8)$ \\
$81-100$ & \\
\hline Gender & $58(50.9)$ \\
male & $56(49.1)$ \\
female & \\
\hline Educational status & $33(28.9)$ \\
primary ( $\leq 6$ years) & $47(41.2)$ \\
secondary (>6-12 years) & $34(29.8)$ \\
tertiary (> 12 years) & \\
\hline Marital status & $9(21.1)$ \\
single & $81(71.1)$ \\
married & $9(7.9)$ \\
divorced/separated &
\end{tabular}

Majority of the participants had glaucoma in both eyes (98 (86.0\%), were on 1 or 2 glaucoma medications (92 (80.7\%)) for less than 5 years $(73(64.0 \%))$, assessed their vision as fair $(65$ $(57.1 \%))$ and were on other regular non-glaucoma prescriptions (70 $(61.0 \%))$. Table 2 shows the clinical characteristics of the participants.

$72(63.2 \%)$ participants were adherent with their glaucoma medications, while $42(36.8 \%)$ were not. Females were more adherent than males, and educated and married people were more adherent to their glaucoma medication.

42 (36.8\%) participants were non-adherent with their glaucoma medications. Being a male, educated, married, having had glaucoma for less than 5 years, having a good understanding of the disease, good/fair vision, using one or two glaucoma medications, assisted administration of medications and living more than $10 \mathrm{~km}$ away from the pharmacy were all associated with non-adherence. Only "assisted administration of medications" was found to be statistically significant $(p=0.001)$.

There was no difference between the mean ages of adherent $(58.25 \pm 15.13)$ and non-adherent $(60.93 \pm 14.56)$ groups.

Table 3 shows the associations of adherence with glaucoma medications. 


\begin{tabular}{|c|c|c|c|c|c|}
\hline \multirow[t]{2}{*}{ Characteristics } & \multirow{2}{*}{$\begin{array}{l}\text { Total (\%) } \\
n=114 \\
\end{array}$} & \multicolumn{2}{|l|}{ Adherence } & \multirow[t]{2}{*}{ OR $(95 \% \mathrm{Cl})$} & \multirow[t]{2}{*}{$p$} \\
\hline & & yes & no & & \\
\hline $\begin{array}{l}\text { Socio-demographics } \\
\text { Mean age (Student } t \text {-test) }\end{array}$ & & $58.25 \pm 15.13$ & $60.93 \pm 14.56$ & $T=0.94$ & 0.36 \\
\hline $\begin{array}{l}\text { Gender } \\
\text { male } \\
\text { female }\end{array}$ & $\begin{array}{l}58(50.9) \\
56(49.1)\end{array}$ & $\begin{array}{l}42(46.7) \\
48(53.3)\end{array}$ & $\begin{array}{l}16(66.7) \\
8(33.3)\end{array}$ & $0.17-1.26$ & $2.28(0.13)$ \\
\hline $\begin{array}{l}\text { Educational status (duration of education) } \\
\leq 6 \text { years } \\
>6 \text { years }\end{array}$ & $\begin{array}{l}33(28.9) \\
81(71.1)\end{array}$ & $\begin{array}{l}25(27.8) \\
65(72.2)\end{array}$ & $\begin{array}{l}8(33.3) \\
16(66.7)\end{array}$ & $0.29-2.02$ & $0.08(0.78)$ \\
\hline $\begin{array}{l}\text { Marital status } \\
\text { married } \\
\text { other }\end{array}$ & $\begin{array}{l}105(92.1) \\
9(7.9)\end{array}$ & $\begin{array}{l}81(90) \\
9(10)\end{array}$ & $\begin{array}{l}24(100) \\
0(0)\end{array}$ & $0.65-0.85$ & $1.41(0.24)$ \\
\hline $\begin{array}{l}\text { Vision } \\
\text { good } \\
\text { poor }\end{array}$ & $\begin{array}{l}72(63.2) \\
42(36.8)\end{array}$ & $\begin{array}{l}59(65.6) \\
31(43.41)\end{array}$ & $\begin{array}{l}13(54.2) \\
11(45.88)\end{array}$ & $0.65-4.01$ & $0.62(0.43)$ \\
\hline $\begin{array}{l}\text { Duration of glaucoma } \\
<5 \text { years } \\
\geq 5 \text { years }\end{array}$ & $\begin{array}{l}73(64) \\
41(36)\end{array}$ & $\begin{array}{l}57(63.3) \\
33(36.7)\end{array}$ & $\begin{array}{l}16(66.7) \\
8(33.3)\end{array}$ & $0.33-2.33$ & $0.04(0.95)$ \\
\hline $\begin{array}{l}\text { Glaucoma medication bottles in use } \\
\quad \leq 2 \\
>2\end{array}$ & $\begin{array}{l}93(81.6) \\
21(18.4)\end{array}$ & $\begin{array}{l}75(83.3) \\
15(16.7)\end{array}$ & $\begin{array}{l}18(75) \\
6(25)\end{array}$ & $0.57-4.89$ & $0.41(0.52)$ \\
\hline $\begin{array}{l}\text { Other eye medication use } \\
\text { yes } \\
\text { none }\end{array}$ & $\begin{array}{l}28(24.6) \\
86(75.4)\end{array}$ & $\begin{array}{l}21(23.3) \\
69(76.7)\end{array}$ & $\begin{array}{l}7(29.2) \\
17(70.8)\end{array}$ & $0.27-2.02$ & $0.11(0.75)$ \\
\hline $\begin{array}{l}\text { Other prescription medications use } \\
\text { yes } \\
\text { no }\end{array}$ & $\begin{array}{l}44(38.6) \\
70(61.4)\end{array}$ & $\begin{array}{l}34(37.8) \\
56(62.2)\end{array}$ & $\begin{array}{l}10(41.7) \\
14(58.3)\end{array}$ & $0.34-2.12$ & $0.012(0.91)$ \\
\hline $\begin{array}{l}\text { Assisted administration of glaucoma } \\
\text { medications } \\
\text { yes } \\
\text { no }\end{array}$ & $\begin{array}{l}52(45.6) \\
62(54.4)\end{array}$ & $\begin{array}{l}33(36.7) \\
57(63.3)\end{array}$ & $\begin{array}{l}19(79.2) \\
5(20.8)\end{array}$ & $0.05-0.45$ & $12.13(0.001)^{*}$ \\
\hline $\begin{array}{l}\text { Distance from pharmacy } \\
\quad<5 \mathrm{~km} \\
>5 \mathrm{~km}\end{array}$ & $\begin{array}{l}43(37.7) \\
71(62.3)\end{array}$ & $\begin{array}{l}35(38.9) \\
55(61.1)\end{array}$ & $\begin{array}{l}8(33.3) \\
16(66.7)\end{array}$ & $0.49-3.28$ & 0.7 (0.79) \\
\hline $\begin{array}{l}\text { Understand the reason for taking your } \\
\text { glaucoma medications } \\
\text { yes } \\
\text { no }\end{array}$ & \begin{tabular}{|l|}
$104(91.2)$ \\
$10(8.8)$
\end{tabular} & $\begin{array}{l}84(93.3) \\
6(6.7)\end{array}$ & $\begin{array}{l}20(83.3) \\
4(16.7)\end{array}$ & $0.72-10.86$ & $1.28(0.25)$ \\
\hline $\begin{array}{l}\text { Side effects of glaucoma medications } \\
\text { yes } \\
\text { no }\end{array}$ & $\begin{array}{l}26(22.8) \\
88(77.2)\end{array}$ & $\begin{array}{l}20(22.2) \\
70(77.8)\end{array}$ & $\begin{array}{l}6(25) \\
18(75)\end{array}$ & $0.30-2.44$ & $0.10(0.99)$ \\
\hline
\end{tabular}

* Significant.

\section{Table 3. Barriers to glaucoma medication adherence}

\begin{tabular}{|l|l|}
\hline Barrier & Frequency \\
\hline It is hard to pay for the medications & $59(51.7)$ \\
\hline Drops fall on cheeks & $42(36.8)$ \\
\hline Too many drops come out at the same time & $36(31.6)$ \\
\hline My medications cause side effects & $16(24.0)$ \\
\hline It is hard to open the bottle & $4(20.2)$ \\
\hline It is hard to get the drops into my eyes & $23(20.2)$ \\
\hline The dosage times are inconvenient & $9(7.9)$ \\
\hline It is hard to squeeze the bottle & $9(7.9)$ \\
\hline It is hard to remember all the doses & $7(6.2)$ \\
\hline My medications cause other problems or concerns & $4(3.6)$ \\
\hline
\end{tabular}

Cost (59 (51.7\%)) was the major deterrent to adherence with glaucoma medications, though poor instillation technique was also an important issue, as shown in Table 3.

\section{Discussion}

The mean age of participants in this study was $59.59 \pm 14.8$ years and comprised more males than females. The majority were married. This socio-demographic profile is similar to that reported in previous studies in Indian [14] and Dutch [13] populations. A majority of the participants in this study had at least primary school education, which contrasts reports from previous similar studies in Ethiopia [15] and other parts of Nigeria [2], where a majority of the participants were illiterate.

In this study, $36.8 \%$ of the participants were non-adherent with their glaucoma medications. This is similar to the $34 \%$ reported in southwest Nigeria [16], but contrasts the $67.5 \%$ reported in Ethiopia [15] and 6\% in India [14]. These previous studies [14-16] and the present one were conducted under similar economic settings (LMICs). The disparity could be due to the different socio-demographic profiles of the participants, and eye health (glaucoma inclusive) could be influenced by literacy levels, financial status and the accessibility of glaucoma 
medications. Interventions aimed at improving adherence with glaucoma medications should therefore be peculiar to the population studied.

In this study, the most important socio-demographic factor that contributed to non-adherence with glaucoma medication was assisted administration of medication. Other factors, such as gender, educational and financial status, duration and understanding of glaucoma and distance from pharmacy, also contributed. The fact that the present study relied on the oral evidence given by the participants might have contributed to the high prevalence observed. Many of the participants (especially the older ones) claimed that their non-adherence was due to failure of the assistant to administer the medication at the right time, as sometimes their assistants were not available for days, and this affected their compliance. Previous studies reported age [8, $9,11,15]$, marital status [14], level of education [9], income [9, 15] and number of medications and frequency of use [12] as the most important factors that contributed to non-adherence with glaucoma medication. Poor instillation technique was the major reason why assistance was needed for drug administration. This implies that when the 'assistant' is not around, the dose is missed. Therefore, more attention should be paid to such patients, and practical and effective ways of drug administration and individualised means of improving adherence should be discussed during clinical consultation. Issues of adherence should become part of the protocol in the management of these patients.

The predominance of males in this study may be due the fact that most males in this area are actively engaged in their work and exhibited a tendency to forget the use of their eye drops amidst their busy schedules. The symptomless nature of early/moderate glaucoma, coupled with the lack of immediate benefit of medications for eyes with good vision gave many of the participants a false sense of security and a feeling of "no cause for alarm".

Cost of drugs was the major deterrent to adherence with glaucoma medications in this study. This is similar to the findings among the southern Indian population [14], where the most common reported problem was paying for medications, and in Ethiopia [15], where $74.4 \%$ of those with financial constraints were non-adherent. In contrast, studies done on Dutch [13], Canadian [12], UK [8] and US [10, 11] populations reported no association between non-adherence with income. However, a younger age [8], forgetfulness [10, 13] and poor instillation technique [13] were the major deterrents.

Patients under functional health insurance schemes would expectedly not have cost as a barrier, but those living below poverty level (as seen in our environment and other LMICs) will find it very difficult to pay for these life-long medications, which are usually expensive. Eye care providers should therefor, take cognisance of this and direct efforts towards the possibilities of making cheaper generic medications available and getting sponsorship for this category of patients.

\section{Conclusions}

The prevalence of non-adherence with glaucoma medications in Enugu was high. The major deterrent to adherence was the cost, while assisted drug administration was a major factor that significantly contributed to non-adherence. The government should develop social health insurance policies designed to assist glaucoma patients living below the poverty line in our environment. Non-governmental organisations and philanthropists should be encouraged to assist this category of patients. Local pharmaceutical companies should be encouraged to produce cheaper but potent generic glaucoma medications.

\section{Recommendations}

This study should be replicated in states in Nigeria where social health insurance is operational, since the major barrier to adherence is cost. This may persuade other states to implement the programme.

Acknowledgments. We appreciate the management of the UNTH, and the Department of Ophthalmology in particular, for allowing us make use of their facility.

Source of funding: This work was funded from the authors' own resources.

Conflicts of interest: The authors declare no conflicts of interest.

\section{References}

1. Kyari F, Gudlavalleti MV, Sivsubramaniam S, et al. Prevalence of blindness and visual impairment in Nigeria: the National Blindness and Visual Impairment Study. Invest Ophthtalmol Vis Sci 2009; 50(5): 2033-2039.

2. Abdull MM, Gilbert CC, Evans J. Primary open angle glaucoma in northern Nigeria: stage at presentation and acceptance of treatment. BMC Ophthalmology 2015; 15(1): 111.

3. Omoti AE, Osahon Al, Waziri-Erameh MJ. Pattern of presentation of primary open angle glaucoma in Benin City Nigeria. Trop Doct 2006; 36(2): 97-100.

4. Lawan A. Pattern of presentation and outcome of surgical management of primary open angle glaucoma in Kano, Northern Nigeria. Ann Afr Med 2007; 6: 180-185.

5. Olawoye OO, Ashaye AO, Baiyeroju AM, et al. Outcomes of trabeculectomy with 5 Fluorouracil at a Nigerian Tertiary Hospital. $J$ Ophthalmic Vis Res 2013; 8(2): 126-133.

6. Heijl A, Leske MC, Bengtsson B, et al. Reduction of intraocular pressure and glaucoma progression: results from the early manifest Glaucoma trial. Arch Ophthalmol 2002; 120(10): 1268-1279.

7. Kass MA, Heuer DK, Higginbotham EJ, et al. The Ocular Hypertension Treatment Study: a randomized trial determines that topical ocular hypotensive medication delays or prevents the onset of primary open-angle glaucoma. Arch Ophthalmol 2002; 120(6): 701-713.

8. Tse AP, Shah M, Jamal N, et al. Glaucoma treatment adherence at a United Kingdom general practice. Eye 2016; 30(8): 1118-1122.

9. Dreer LE, Girkin C, Mansberger SL. Determinants of medication adherence to topical glaucoma therapy. J Glaucoma 2012; 21(4): 234-240.

10. Stryker JO, Beck AD, Primo SA, et al. An exploratory study of factors influencing glaucoma treatment adherence. J Glaucoma 2010; 19(1): 66-72.

11. Bacon TS, Fan KC, Desai MA. Electronic medical record and glaucoma medications: connecting the medication reconciliation with adherence. Clin Ophthalmol 2016; 10: 221-225.

12. Djafari F, Lesk MR, Harasymowycz PJ, et al. Determinants of adherence to glaucoma medical therapy in a long-term patient population. J Glaucoma 2009; 18(3): 238-243.

13. Olthoff CMG, Hoevenaars JGMM, Borne BW Van den, et al. Prevalence and determinants of non-adherence to topical hypotensive treatment in Dutch glaucoma patients. Graefes Arch Clin Exp Ophthalmol 2008, doi: 10.1007/s00417-008-0944-y. 
14. Sleath BL, Krishnadas R, Cho M, et al. Patient reported barriers to glaucoma access, use and adherence in southern India. Indian J Ophthalmol 2009; 57: 63-68.

15. Tamarat L, Gessesse GW, Gelaw Y. Adherence to topical glaucoma medications in Ethiopian patients. Middle East Afr J Ophthalmol 2015; 22(1): 59-63.

16. Omolase CO, Ogunleye OT, Sotiloye OA, et al. Compliance with topical glaucoma medications in Owo Nigeria. Brunei Int med J 2013; 9(3): 172-177.

17. Onakoya AO, Mbadugha CA. Self-reported adherencerates in glaucoma patients in Southwest Nigeria. J Clin Sci 2016; $13: 51-57$.

18. Abdull MM, Gilbert C, McCambridge J, et al. Adapted motivational interviewing to improve the uptake of treatment for glaucoma in Nigeria: study protocol for a randomised controlled trials. Trials 2014; 15(1): 149.

19. Usifoh SF, Udezi WA, Omage JO. Prevalence of glaucoma in a Nigerian hospital. J Pharmacy Biosciences 2014; 11(1): 22-28.

Tables: 3

Figures: 0

References: 19

Received: 27.09 .2019

Reviewed: 19.10 .2019

Accepted: 3.12 .2019

Address for correspondence:

Nkiru Zuadae Nwachukwu, MD

Department of Ophthalmology

University of Nigeria Teaching Hospital

PMB 01129, Ituku-Ozalla

Enugu

Nigeria

Tel.: +234 803-3287938

E-mail: zuadae80@yahoo.com 